\title{
ERÄITÄ LISÄSELVITYKSIÄ VUODEN 1953 PERUNARUTTO- [PHYTOPHTHORA INFESTANS (MONT.) de BARY] EPIDEMIAN LUONTEESTA
}

\author{
Onni Pohjakallio \\ Helsingin yliopiston kasvipatologinen laitos, Helsinki
}

Saapunut 17, 4. 1954

Kesällä 1953 vallitsi etelä-Suomessa tavallista ankarampi perunaruttoepidemia (vert. 2, 4, 8). Rutto ilmestyi varhain; aikaisten perunalajikkeiden varret tuhoutuivat jo heinä-elokuun vaihteessa ja elokuun kuluessa useimpien myöhäistenkin lajikkeiden kasvu keskeytyi ruton turmelemana. Maatalouskoelaitoksen kasvinjalostusosaston kokeissa Jokioisissa rutto saastutti ankarasti myös Aquila-perunaa ja useita perunan lajiristeytysklooneja, jotka aikaisempina vuosina olivat osoittautuneet käytännöllisesti katsoen täysin rutonkestäviksi $(4,5)$.

Vaikkakin perunaruttoa esiintyi kautta etelä-Suomen runsaasti, vaihteli epidemian ankaruus eri paikkakunnilla melkoisesti. Niinpä Jokioisissa myöhäistenkin

Taulukko 1. Perunaruton esiintyminen Viikin koetilan kenttäkokeissa 1949-1953.

Table 1. Potato blight in field experiments at Viik 1949-1953.

\begin{tabular}{|c|c|c|c|c|c|c|c|c|c|c|c|c|c|}
\hline \multirow{3}{*}{$\begin{array}{l}\text { Perunalajike } \\
\text { Variety }\end{array}$} & \multicolumn{8}{|c|}{$\begin{array}{l}\text { Lehtiruttoa }(10=\text { terve }) \\
\text { Blight on the haulms }(10=\text { no blight })\end{array}$} & \multicolumn{5}{|c|}{$\begin{array}{l}\text { Mukularuttoa } \% \\
\text { Blight on the tubers } \%\end{array}$} \\
\hline & 1949 & 1950 & 1951 & & 952 & & 1953 & & 1949 & 1950 & 1951 & 1952 & 1953 \\
\hline & $15 / 9^{1}$ & & & $3 / 9$ & $10 / 9$ & $\begin{array}{l}\text { Rutto } \\
\text { ilmesty } \\
\text { The blig } \\
\text { appeare }\end{array}$ & $22 / 8$ & $1 / 9$ & & & & & \\
\hline Rosafolia $\ldots \ldots \ldots \ldots$ & $(3.8)$ & 10.0 & 10.0 & 8.3 & 4.9 & $6 / 8$ & 4.0 & 1.7 & 0.1 & 0.0 & 0.0 & 0.0 & 0.0 \\
\hline Aquila $\quad \ldots \ldots \ldots \ldots \ldots$ & $(9.3)$ & 10.0 & 10.0 & 10.0 & 9.7 & $1 / 9$ & 10.0 & 9.8 & 0.0 & 0.0 & 0.0 & 0.0 & 0.0 \\
\hline King George $\mathrm{V} \ldots \ldots \ldots$ & $(1.9)$ & 10.0 & 10.0 & 4.5 & 1.4 & $31 / 7$ & 2.9 & 0.0 & 0.0 & 0.0 & 0.0 & 0.0 & 1.7 \\
\hline Ostbote $\ldots \ldots \ldots \ldots \ldots$ & $(8.0)$ & 10.0 & 10.0 & 8.7 & 8.1 & $31 / 7$ & 7.3 & 5.8 & 0.0 & 0.0 & 0.0 & 0.0 & 1.8 \\
\hline 565 (S. tuber. $\times$ S. dem.) & 10.0 & 10.0 & 10.0 & 10.0 & 10.0 & - & 10.0 & 10.0 & 0.0 & 0.0 & 0.0 & 0.0 & 0.0 \\
\hline$\longrightarrow-$ & 10.0 & 10.0 & 10.0 & 10.0 & 10.0 & - & 10.0 & 10.0 & 0.0 & 0.0 & 0.0 & 0.0 & 0.0 \\
\hline Harbinger $1 \quad \ldots \ldots \ldots$. & $(0.0)$ & 10.0 & 10.0 & 0.0 & 0.0 & $27 / 7$ & 0.0 & 0.0 & 3.9 & 0.0 & 0.0 & 3.5 & 4.2 \\
\hline$-"-2 \ldots \ldots \ldots$ & - & 10.0 & 10.0 & 0.0 & 0.0 & $25 / 7$ & 0.0 & 0.0 & - & 0.0 & 0.0 & 10.0 & 7.3 \\
\hline
\end{tabular}

1) Luvut ilmaisevat varsiston terveyden $(0-10 ; 10=$ terve). Ruton ohella ilmeni lievää hallan tuhoa; esim. Aquila-perunassa ei lehtiruttoa varmuudella todettu. Kerrannaisruutuja oli 4. 
Taulukko 2. Heinä-elokuun sademäärä Viikissä ja Jokioisissa v. 1953 (9).

Table 2. Precipitation during July-August at Viik and Jokioinen (9).

\begin{tabular}{|c|c|c|c|c|}
\hline 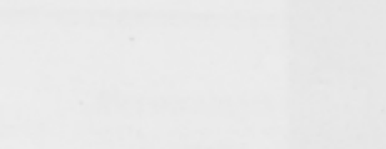 & \multicolumn{2}{|c|}{$\begin{array}{l}\text { Heinäkuu } \\
\text { (mm) } \\
\text { July }\end{array}$} & \multicolumn{2}{|c|}{$\begin{array}{l}\text { Elokuu } \\
(\mathrm{mm}) \\
\text { August }\end{array}$} \\
\hline & 1953 & $\begin{array}{c}\text { Normaali } \\
\text { Normal }\end{array}$ & 1953 & $\begin{array}{c}\text { Normaali } \\
\text { Normal }\end{array}$ \\
\hline Jokioinen $\ldots \ldots \ldots$. & 117 & 77 & 101 & 79 \\
\hline Helsinki $\ldots \ldots \ldots \ldots$ & 121 & 59 & 65 & 83 \\
\hline
\end{tabular}

perunalajikkeiden, mm. Aquila-perunan varsisto tuhoutui jo elokuun kuluessa lähes täydellisesti (4). Rutto siirtyi siellä myös mukuloihin turmellen $50-90 \%$ arimpien, $10-20 \%$ useimpien muiden lajikkeiden sekä $3-5 \%$ Rosafolia- ja Aquila-perunain sadoista (5). Helsingin yliopiston kasvipatologisen laitoksen kokeissa Viikin koetilalla perunaruton tuho oli selvästi lievempi (taulukko 1). Tosin täälläkin lehtiruttoa ilmestyi perunan varsiin jo heinäkuun lopulla ja ruton tuhot olivat ankarammat kuin aikaisempina vuosina, mutta Aquila-peruna ja lajiristeytyskloonit (Solanum tuberosum $\times S$. demissum, $\mathrm{F}_{1}$-polvi) säilyivät edelleen käytännöllisesti katsoen täysin terveinä. Mukularuttoa esiintyi tuskin enemmän kuin edellisenä vuonna. Turmiollisin se oli Harbinger-perunalle; varsinkin sen virustautisista istutusmukuloista kehittynyt kasvusto (Harbinger 2) saastui ankarasti.

Perunaruton erikoisluontoiseen esiintymiseen Jokioisissa lienee sääsuhteilla ollut oma osuutensa. Siellä olivat nimittäin sekä heinä- että elokuu poikkeuksellisen sateiset (taulukko 2). Helsingissäkin heinäkuu oli tavallista paljon sateisempi, mutta elokuun sademäärä oli sen sijaan suhteellisen niukka.

Aquila-perunan yllättävä sairastuminen Jokioisissa viittaisi myös mahdollisuuteen, että siellä olisi päässyt valtaan tavanomaista patogenisempi perunarutto-

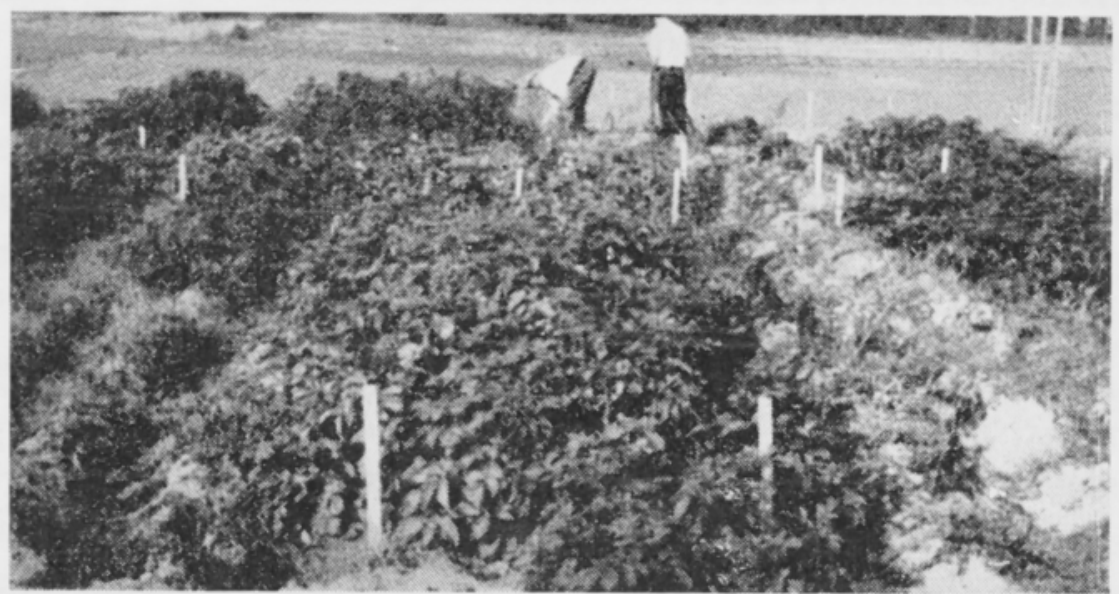

Kuva 1. Aquila peruna Viikin koetilan kokeissa v. 1949

(Rutonarat lajikkeet Aquila-perunan molemmin puolin ovat ruton täysin kulottamia).

Fig. 1. Aquila potato in field experiments at Viik 1949.

(The haulms of the susceptible varieties on either side of the Aquila potato are completely rotted). 


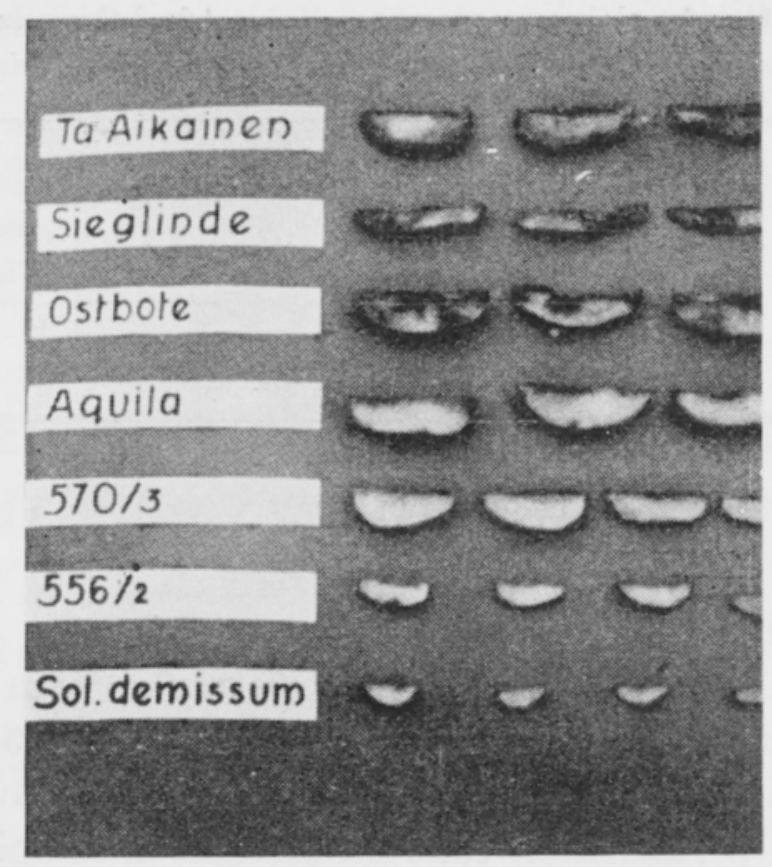

Kuva 2. Perunan mukulain ruttosaastutus v. 1949.

Fig. 2. Experiments 1949.

sienirotu. Onhan ulkomailla monesti todettu perunaruttoepidemian johtuvan uuden patogenisen rodun ilmaantumisesta. Sitä paitsi tiedetään, että perunaruton patogenisia rotuja on kaikkiaan ainakin 13 ja ettei ainoakaan perunalaji eikä lajike ole osoittautunut niistä jokaista vastaan kestäväksi $(1,7)$.

Yliopiston kasvipatologisen laitoksen aikaisemmissa tutkimuksissa monet lajiristeytyskloonit (Solanum tuberosum $\times$ S. demissum) samoin kuin Aquila-peruna olivat osottautuneet hyvin kestäviksi etelä-suomalaista perunaruttoaineistoa vastaan (3, kuva 2). Kestävyys ilmeni mukulain infektiokokeissa erityisen selvästi (kuva 2). Näin ollen mukulainfektioita suoritettiin myös kesän 1953 perunaruttoaineistoilla. Ruttoisia mukuloita saatiin maatalouskoelaitoksen kasvinjalostus-

Taulukko 3. Rosafolia-perunan mukulain saastutus eri perunaruttomateriaaleilla.

Table 3. Infection of the potato variety Rosafolia with different strains of Phytophthora infestans.

\begin{tabular}{cccc}
\hline & $\begin{array}{c}\text { Perunaruttosieniaineisto } \\
\text { Source of the fungus }\end{array}$ & $\begin{array}{c}\text { Mukulan ruskettuminen } \\
(10=\text { täysin ruskettunut }) \\
(0-10)\end{array}$ \\
No & $\begin{array}{c}\text { Paikkakunta } \\
\text { Parish }\end{array}$ & $\begin{array}{c}\text { Perunalajike } \\
\text { Potato variety }\end{array}$ & $\begin{array}{c}\text { Dry rot on the tubers } \\
(10=\text { fully decayed })\end{array}$ \\
\hline
\end{tabular}

\begin{tabular}{rlll}
\hline 3 & Ruukki & Harbinger & 4 \\
4 & Ylistaro & Bintje & 4 \\
5 & Anjala & King George V & 1,5 \\
6 & Jokioinen & Jaakko & 1 \\
7 & $-1-$ & Aquila & 9 \\
10 & Helsinki & Tammiston & 4 \\
11 & Rovaniemi & $?$ & 3.5
\end{tabular}


Taulukko 4. Perunalajikkeiden mukulain saastutuskokeiden tulokset v. 1953.

Table 4. Results of experiments in which the tubers of three potato varieties were infected with potato blight fungus from different sources.

\begin{tabular}{|c|c|c|c|}
\hline \multirow{2}{*}{$\begin{array}{l}\text { Perunalajike } \\
\text { Variety }\end{array}$} & \multicolumn{3}{|c|}{$\begin{array}{c}\text { Perunaruttosieniaineistot } \\
\text { Source of Phytophthora infestans }\end{array}$} \\
\hline & $\begin{array}{c}10 \\
(\text { Helsinki) }\end{array}$ & $\begin{array}{c}\quad 7 \\
\text { (Jokioinen) }\end{array}$ & $\begin{array}{c}11 \\
\text { (Rovaniemi) }\end{array}$ \\
\hline
\end{tabular}

A. Mukulan ruskettum in en $(0-10)$

Dry rot on the tubers

$\begin{array}{llll}565 \text { (S. tuber. } \times \text { S. dem.) } \ldots & 0 & 8 & 0+ \\ \text { Aquila } \ldots \ldots \ldots \ldots \ldots \ldots \ldots & 0 & 7 & 0+ \\ \text { Tammisto } \ldots \ldots \ldots \ldots \ldots \ldots & 7 & 8 & 6\end{array}$

B. Kurom a n u o dost us $(-=$ ei, $+++=$ runsaasti $)$

Fructification of the fungus $(-=n o,+++=$ in abundance)

565 (S. tuber. $\times$ S. dem.) ..

Aquila

Tammisto
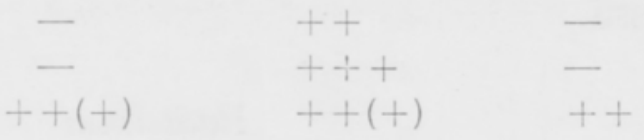

osastolta Jokioisista ja kasvinviljelykoeasemilta eri puolilta Suomea. Saastutukset suoritettiin ns. viipaleinfektioina: perunat halkaistiin, puoliskojen väliin pantiin ohut viipale ruttoisen mukulan maltoa, puoliskot naulattiin tikulla takaisin toisiinsa kiinni ja avattiin kahden vuorokauden kuluttua (aikaisemmissa kokeissa käytettiin viipaleiden ohella myös kuromasuspensioita). Saastutetut mukulat pidettiin koeaikana vesiastian päällä, lasikuvun alla huoneessa, jonka ilman kosteus oli n. $90 \%$; kerrannaisia oli 4 .

Alustavissa kokeissa todettiin, että Jokioisissa Aquila-perunassa esiintynyt perunaruton aiheuttaja saastutti Rosafolia-perunaa erityisen ankarasti (taulukko 3). Samalta paikkakunnalta Jaakko-perunasta saadun perunaruttosienimateriaalin patogeniteetti ilmeni tässä mukularuttoa vastaan suhteellisen kestävänä pidettävässä lajikkeessa sen sijaan vain varsin heikkona. Onkin tunnettua, että perunaruttosienen uudet patogeniset rodut esiintyvät puhtaimpina niissä perunalajikkeissa, jotka ovat entistä ruttoaineistoa vastaan kestäviä (vrt. 6). Saastuneita Aquilaperunan mukuloita ei löydetty muualta kuin Jokioisista, vaikka niitä erityisesti etsittiin.

Varsinaisissa saastutuskokeissa (taulukko 4) vahvistui käsitys siitä, että Jokioisissa Aquilaa saastuttaneen perunaruttoaineiston patogeniteetti oli erityisen voimakas (kuva 3). Se saastutti jokaista kolmea tutkittua perunalajiketta jokseenkin yhtä ankarasti. Helsingistä (Viikin koetilalta) peräisin olevan ruttomateriaalin patogeniteetti ilmeni sen sijaan jokseenkin samanlaisena kuin aikaisempina vuosina suoritetuissa kokeissa (vrt. kuva 2); se rusketutti voimakkaasti Tammiston aikaisen perunan maltoa, mutta ei vioittanut Aquila-perunan eikä lajiristeytyskloonin mukuloita. Aikaisempiin tuloksiin verrattuna ilmeni kuitenkin se eroavaisuus, että myös kuromannuodostus oli Tammiston aikaisen perunan mukuloissa runsasta; 


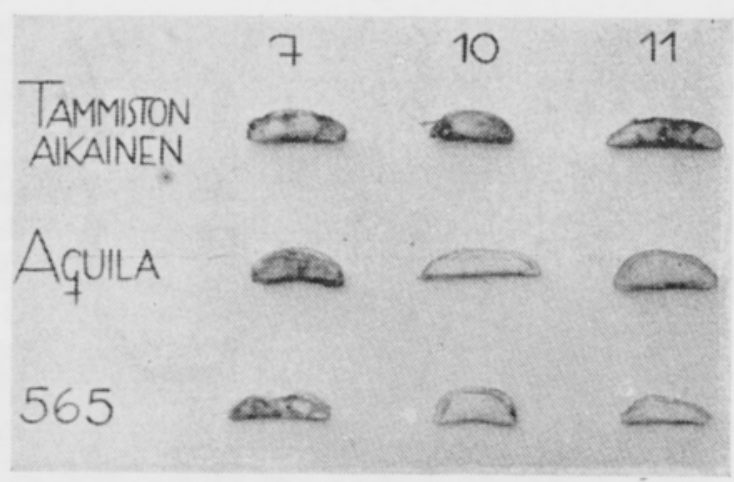

Kuva 3. Perunan mukulain ruttosaastutus v. 1953.

Fig. 3. Experiments 1953.

ennen niiden oli todettu vain ruskettuvan, mutta perunaruttosienen kuromia niissä muodostui tuskin ollenkaan (3). Oliko tähän syynä mukulain toisenlainen fysiologinen tila, koeolosuhteiden vai perunaruttosienimateriaalin erilaisuus, ei enää ollut selvitettävissä.

\section{Päätelmät}

Edellä selostetuissa tutkimuksissa ilmeni, että kesällä 1953 esiintyi Suomessa patogeniteetiltaan erilaisia perunaruttosienirotuja.

Eräs perunaruttosienirotu, jota esiintyi ainakin Jokioisissa, saastutti ankarasti myös Aquila-perunaa ja perunan lajiristeytyksestä saatuja klooneja, jotka aikaisempina vuosina ovat olleet perunaruttoa vastaan käytännöllisesti katsoen täysin kestävät.

KIRJALLISUUTTA

(1) Black, W., Masterbrock, C., Millis, W. R. \& Peterson, L. C. 1953. A proposal for an international nomenklature of races of Phytophthora infestans and of genes controlling immunity in Solanum demissum derivates. Euphytica, p. 173-179

(2) Jamalainen, E. A. 1953. Maaseudun tulevaisuus, 37 (13. 8. 1953).

(3) Pohjakallio, Onni 1950. Potatisens resistensfrågor. Nordisk Jordbruksforskning, 2-3, 1951, p. $486-492$.

(4) Pohjanheimo, Onni 1953. Maaseudun tulevaisuus, 37 (12.9. 1953).

(5) - 1953. Ibid. (24, 10. 1953).

(6) Roemer, Th., Fuchs, W. H. \& Isenbeck, K.'1938. Die Züchtung resistenter Rassen der Kulturpflanzen. Berlin.

(7) Stelzner, G. \& Lehmann, H. 1939. Kartoffel, Solanum tuberosum L. (Roemer-Rudorf Handbuch der Pflanzenzüchtung 1939, p. 96-176). Berlin.

(8) YlimäKi, Aarre 1953. Maaseudun tulevaisuus, 37 (25. 8. 1953).

(9) Kunkausikatsaus Suomen sääoloihin 4\%. Helsinki. 


\title{
SUMMARY:
} SOME FEATURES OF THE PHYTOPHTHORA INFESTANS EPIDEMIC IN THE SUMMER
OF 1953

\author{
Onni Pohjakallio
}

Department of Plant Pathology, University of Helsinki.

In summer 1953 the potato blight caused serious damage to haulms and tubers of the potato, particularly in the southern parts of Finland $(2,4,8)$. At the same time the existence was established of various strains of Phytophthora infestans, appearing to differ in their pathogenity to the potato (Table 3). One strain of the fungus, which appeared in the parish of Jokioinen at least, also attacked the potato variety Aquila and Solanum tuberosum $\times$ S. demissum clones (Table 4, Fig. 3), which had previously been regarded in Finland as resistant to the potato blight (Table 1, Figures 1 and 2). In the parish of Jokioinen, where the potato blight epidemic proved extremely severe, the months of July and August were much more rainy than usual (Table 2). 